\title{
The Distribution of Firm Size and Aggregate Investment
}

Vito D. Gala

University of Pennsylvania

Brandon Julio

Follow this and additional works at: https://repository.upenn.edu/fnce_papers

Part of the Finance and Financial Management Commons

\section{Recommended Citation}

Gala, V. D., \& Julio, B. (2012). The Distribution of Firm Size and Aggregate Investment. http://dx.doi.org/ $10.2139 /$ ssrn.2023903

This paper is posted at ScholarlyCommons. https://repository.upenn.edu/fnce_papers/12

For more information, please contact repository@pobox.upenn.edu. 


\title{
The Distribution of Firm Size and Aggregate Investment
}

\begin{abstract}
We investigate empirically how the distributional dynamics of firm investment rates and firm size affect aggregate US investment during the period 1962-2006. We find that the cross-sectional covariation between firms' investment rates and their relative size accounts on average for about half of aggregate investment rate. The negative sign of this covariance implies that a mean-preserving increase in the cross-sectional dispersion of investment rates and/or relative size reduces aggregate investment rate. We investigate the implications of firm-level conditional convergence in corporate investment rates on the dynamics of aggregate investment. We identify the cross-sectional variance of firm relative size as being particularly relevant to explain aggregate investment dynamics. With aggregate NIPA investment data, the cross-sectional variance of firm size fits the investment equation better than the traditional measure of Tobin's Q and it drives out cash flow.
\end{abstract}

\section{Keywords}

investment, tobin's $Q$, cash flow, firm size

Disciplines

Finance and Financial Management 


\title{
The Distribution of Firm Size and Aggregate Investment
}

\author{
Vito D. Gala and Brandon Julio* \\ London Business School
}

March 2012

\begin{abstract}
We investigate empirically how the distributional dynamics of firm investment rates and firm size affect aggregate US investment during the period 1962-2006. We find that the cross-sectional covariation between firms' investment rates and their relative size accounts on average for about half of aggregate investment rate. The negative sign of this covariance implies that a mean-preserving increase in the cross-sectional dispersion of investment rates and/or relative size reduces aggregate investment rate. We investigate the implications of firm-level conditional convergence in corporate investment rates on the dynamics of aggregate investment. We identify the cross-sectional variance of firm relative size as being particularly relevant to explain aggregate investment dynamics. With aggregate NIPA investment data, the cross-sectional variance of firm size fits the investment equation better than the traditional measure of Tobin's $\mathrm{Q}$ and it drives out cash flow.
\end{abstract}

${ }^{*}$ Department of Finance, London Business School, Regent's Park, London NW1 4SA, United Kingdom; e-mail: vgala@london.edu; bjulio@london.edu. We thank John Cochrane, George Constantinides, Francisco Gomes, Joao Gomes, Lars Hansen, John Heaton, Christopher Hennessy, Monika Piazzesi, Pietro Veronesi and seminar participants at the Hong Kong University of Sciene and Technology, London Business School, University of Chicago, University of New South Wales, and the Wharton Business School for helpful comments and suggestions. All errors are our own. 


\section{Introduction}

"Few economists or business analysts need be reminded of the importance of investment. First, investment contributes to future output; net investment to economic growth. Second, it contributes to current demand and current employment. Understandably, there is much sentiment for encouraging investment, or at least for removing discouraging influences, to permit these contributions to be optimal.". Robert Eisner (1978)1

The performance of countries and firms is often measured along the investment dimension as investment provides a base for future growth. Many economists have researched theoretically and empirically the determinants of investment either at the micro-level or at macro-level, but relatively few have focused on the implications of micro-level investments on the aggregates 2 While most of the existing literature on the latter focuses on the importance of microeconomic lumpiness and investment frictions for aggregate investment dynamics, we investigate empirically how the properties of corporate investments and the distribution of firm size affect the dynamics of aggregate investment.

This paper delivers several main contributions. First, using aggregated firm-level data, we investigate the importance of distributional dynamics in investment rates and firm relative size (a firm's capital stock normalized by aggregate capital stock) for aggregate investment. Specifically, we decompose the aggregate investment rate - i.e. capitalweighted average of firm investment rates - as the sum of the equal-weighted average of firm investment rates, and the cross-sectional covariation between firms' investment rates and their relative size. For expositional convenience, we refer to this covariance term as the "distributional wedge". During the sample period 1962-2006, the average distributional wedge is about $-10 \%$ per annum, accounting (in absolute value) on av-

\footnotetext{
${ }^{1}$ Citation from Ricardo J. Caballero (2000).

${ }^{2}$ The literature on investment is vast. For a summary of the main contributions of investment at the micro-level see Stein (2003), and at the aggregate level see Caballero (2007). For the aggregate implications of micro-level investments mostly focusing on their lumpiness see Caballero and Engel (1993, 1999), Caballero, Engel and Haltiwanger (1995), Abel and Eberly (2002), Thomas (2002), Gourio and Kashyap (2007), among others.
} 
erage for as much as $56 \%$ of the aggregate investment rate. This provides preliminary model-free evidence that firm heterogeneity in growth rates and size is indeed important for aggregate growth. The negative cross-sectional covariation between firms' investment rates and their relative size implies that a mean-preserving increase in the cross-sectional dispersion of investment rates and/or relative size reduces the aggregate investment rate. When controlling for the average firm investment rate, we estimate that a one-standard deviation increase in the cross-sectional dispersion of firm investment rates decreases on average aggregate investment rates by about $1.6 \%$ per annum. Similarly, because of the negative cross-sectional correlation between investment rates and relative size, an increase in the cross-sectional dispersion of relative size dampens aggregate investment as a capital-weighted average of investment rates now assigns even more weight to firms with lower investment rates. We estimate that a one-standard deviation increase in the cross-sectional dispersion of firm relative size dampens on average aggregate investment by about $0.8 \%$ per annum.

Second, building upon the empirical evidence in Gala and Julio (2010), we establish empirically (conditional) convergence in corporate investment rates. A firm's investment rate is negatively related to its size, even after controlling for factors known to affect a firm's optimal investment rate including Tobin's $Q$ and cash flow. We then investigate the implications of firm-level convergence on the dynamics of aggregate investment. Specifically, because of conditional convergence in investment rates, we identify the crosssectional variance of firm relative size as being particularly relevant to explain aggregate investment dynamics. Adding the cross-sectional variance of firm relative size to the standard aggregate investment regression with Tobin's Q and cash flow substantially improves the explanatory power of aggregate investment dynamics. The adjusted $R^{2}$ increases by 13 percentage points corresponding to a more than threefold increase from the standard investment regression. A one standard deviation increase in the crosssectional variance of firm relative size decreases the aggregate investment rate by about 1.4 percentage points. The economic significance of the impact on aggregate investment of the cross-sectional variance of firm relative size is as large as the impact of aggregate cash flow and four times as large as the impact of aggregate Tobin's Q. These findings are robust to common potential problems associated with estimating investment regressions 
including measurement errors, different lag structures, simultaneity bias, alternative specifications of the investment regression, and sample selection.

We assess further the importance of firm-level conditional convergence by comparing the aggregate rate of investment observed in the data to that predicted by the firmlevel investment specification and its aggregated counterpart. This gauges how well the firm-level estimates fare with the aggregated firm-level estimates in predicting aggregate values. We find that accounting for conditional convergence substantially improves the forecasting performance of standard aggregate linear investment equations, particularly when the estimates are based on aggregated firm-level data.

Finally, we also examine the importance of accounting for firm convergence on actual aggregate investment from NIPA. Interestingly, we find that the inclusion of the crosssectional variance of firm size drives out aggregate cash flow in a traditional augmented Q-type regression. Overall, the results confirm that the cross-sectional variance of firm size affects significantly the dynamics of aggregate investment.

Our paper contributes to the literature that focuses on explaining the dynamics of aggregate investment. Tobin's (1969) Q-theory of investment, and the subsequent contributions of Abel (1979), Hayashi (1982) and Gomes (2001) have provided the foundation for a large body of empirical work on aggregate investment. Among others, Abel and Blanchard (1986) find that marginal q as measured by the present value of future profits, although significantly related to investment, leaves unexplained a large part of the movement in investment. Barro (1990) finds that changes in stock prices have substantial explanatory power for US. investment, especially for long term samples, and even in the presence of cash-flow variables. Blanchard, Rhee and Summers (1993) investigate the relation between investment, market valuation, and proxies for fundamentals over a long period of time, 1900-1990, and around episodes associated with the crashes of 1929 and 1987. They provide evidence of a limited role of market valuation, given fundamentals. More recently, Hassett and Hubbard (1997) show that in aggregate U.S. data the unconditional correlation between cost of capital and investment is low, and so is that between average $\mathrm{q}$ and investment. On the other hand, cash flows and sales's growth closely track aggregate investment. Using aggregated firm-level data during the period 
1962-2006, our paper confirms the importance of proxies for fundamentals in explaining the dynamics of aggregate investment. Moreover, after establishing firm-level convergence in investment rates, we investigate its aggregate implications by identifying the cross-sectional variance of firm relative size as being an additional important variable to track aggregate investment.

More recently, a growing literature in economics has focused on the implications of microeconomic investment frictions on the aggregates. Bertola and Caballero (1994) investigate the aggregate implications of microeconomic irreversibility and idiosyncratic uncertainty in a partial equilibrium framework. Gala (2006) characterizes the general equilibrium aggregate implications of firm-level investment irreversibility in the presence of persistent aggregate and idiosyncratic productivity shocks. Starting with the basic premise that understanding aggregate dynamics requires considering agents' heterogeneity and infrequent adjustment to perceived shocks, Caballero and Engel (1991) provide a framework to study the aggregate dynamic behavior of an economy where individual units follow (S, s) policies. Caballero and Engel (1993) then provide a general characterization of lumpy behavior at the microeconomic level in terms of an adjustment-hazard function, and Caballero and Engel (1999) investigate the aggregate implications of generalized $(\mathrm{S}, \mathrm{s})$ firm investment policies on postwar U.S. manufacturing investment data. The work of Doms and Dunne (1993) documents that investment spikes account for a large fraction of the investment of a large group of manufacturing plants from the Longitudinal Research Database. Caballero, Engel, and Haltiwanger (1995) characterize this pattern further emphasizing that microeconomic investment is extremely lumpy, and this lumpiness is unlikely to fully "wash out" at the aggregate level. Thomas (2002) and Gourio and Kashyap (2007) investigate theoretically and empirically the general equilibrium implications of lumpy investments at the establishment-level on aggregate investment. Abel and Eberly (2002) use panel data to estimate a model of optimal investment allowing for fixed, linear, and convex adjustment costs. They find evidence of both statistically and economically important nonlinearities, potentially arising from fixed costs, in the relationship between investment and its determinants. These nonlinearities imply that the cross-sectional distribution of q affects aggregate investment, so that the nonlinear model predicts aggregate investment substantially more success- 
fully than does the linear model, particularly during large cyclical fluctuations. Eberly (1997) provides evidence on the importance of firm-level nonlinearities in international data. Our paper contributes to this literature by investigating empirically how a different property of microeconomic investments, namely firm-level convergence in investment rates, affects the dynamics of aggregate investment.

The paper proceeds as follows. Section 2 discusses the aggregate investment decomposition, the notion of convergence in corporate investment rates and its implication for aggregate investment dynamics. Section 3 describes the data used in our empirical analysis and provides the main empirical results concerning the dynamics of aggregate investment. Section 4 concludes.

\section{Aggregate Investment}

In this section we provide a model-free decomposition of aggregate investment to investigate and quantify the importance of firms' distributional dynamics. Building on Gala and Julio (2010), we then establish conditional convergence in corporate investment rates, and investigate the implications of the firm-level convergence analysis on the dynamics of aggregate investment.

\section{A. Aggregate Investment Decomposition}

Aggregate investment does not stem from investment decisions taken at the aggregate economy level, but rather is the result of aggregated firm-level investment decisions. Let $i_{i, t+1} \equiv I_{i, t+1} / K_{i, t}$ denote firm $i$ 's investment rate between time $t$ and $t+1$, and $k_{i, t} \equiv K_{i, t} / K_{t}$ denote firm $i$ 's relative size at time $t$, with $K_{t} \equiv \frac{1}{N_{t}} \sum_{j=1}^{N_{t}} K_{j, t}$ being the average firm's capital stock at time $t$. Then, we can decompose the aggregate investment rate $i_{t} \equiv I_{t+1} / K_{t}$, i.e. the ratio of aggregated firm-level investments to aggregated firmlevel capital stocks, as

$$
\underbrace{i_{t+1}}_{\text {Aggregate Invest. }} \equiv \frac{E^{i}\left[I_{i, t+1}\right]}{E^{i}\left[K_{i, t}\right]}=E^{i}\left[i_{i, t+1} k_{i, t}\right]=\underbrace{E^{i}\left[i_{i, t+1}\right]}_{\text {Average Invest. }}+\underbrace{\operatorname{Cov}^{i}\left(i_{i, t+1}, k_{i, t}\right)}_{\text {Distributional Wedge }}
$$


where superscript $i$ denotes cross-sectional sample moments, i.e. $E^{i}[\cdot] \equiv \frac{1}{N} \sum_{i=1}^{N}[\cdot]$. The last equality follows from $E^{i}\left[k_{i, t}\right]=1$ as implied by the definition of relative size $k_{i, t} \equiv K_{i, t} / E^{i}\left[K_{i, t}\right]$. The aggregate investment rate can be decomposed as the sum of the average firm investment rate $E^{i}\left[i_{i, t+1}\right]$, and the cross-sectional covariation between firms' investment rates and relative size, $\operatorname{Cov}^{i}\left(i_{i, t+1}, k_{i, t}\right)$. For expositional convenience, we refer to this covariance term as the "distributional wedge".

The decomposition in (11) highlights the impact of the distributional dynamics of firms' investment rates and relative sizes on aggregate investment. The distributional wedge provides a model-free estimate of this impact.

The investment wedge can be further rewritten as $\operatorname{Cov}^{i}\left(i_{i, t+1}, k_{i, t}\right)=\rho^{i}\left(i_{i, t+1}, k_{i, t}\right) \sigma^{i}\left(i_{i, t+1}\right) \sigma^{i}\left(k_{i, t}\right)$, where $\rho^{i}$ and $\sigma^{i}$ denote cross-sectional correlation and standard deviation, respectively. As long as there is a relation between a firm's growth and its relative size - i.e. $\rho^{i} \neq 0$ the degree of inequality in growth and size across firms matters for aggregate investment. For instance, if $\rho^{i}<0$, then an increase in the cross-sectional dispersion of firms' relative sizes, $\sigma^{i}\left(k_{i}\right)$, depresses aggregate investment, ceteris paribus. Intuitively, an increase in the cross-sectional dispersion of firms' relative sizes shifts the mass towards the tails of its distribution, while leaving unchanged its cross-sectional mean, $E^{i}\left[k_{i}\right]=1$. When $\rho^{i}<0$, a firm's growth is negatively related to its relative size. Hence, this redistribution of firms' relative sizes across firms with different investment rates depresses aggregate investment since a capital-weighted average of investment rates now assigns even more weight to large firms with low investment rates. Similarly, a "mean-preserving" increase in the cross-sectional dispersion of firms' investment rates or their determinants reduces aggregate investment, ceteris paribus. The higher $\rho^{i}$, the larger the impact of a "meanpreserving" increase in spread on aggregate investment.

\section{B. Firm-Level Convergence}

In the economic growth literature, the notion of convergence is typically applied to countries or regions within countries 3 However, the same notion of convergence can

\footnotetext{
${ }^{3}$ See Barro (1984), Baumol (1986), Barro and Sala-i-Martin (1992), Mankiw, Romer and Weil (1992), and Sala-i-Martin (1996), among others.
} 
generally by applied to any economic unit. In this section, we investigate convergence of firms' growth within an economy. Building upon the existing investment literature and the convergence analysis in Gala and Julio (2010), we focus on corporate investment rates as measure of a firm's growth.

The notion of convergence relates to the mobility of different firms within the given distribution of firm size. The basic idea of convergence, more precisely of $\beta$-convergence, requires a firm's growth rate to be positively related to the distance between a firm's current capital stock and its own optimal value. The literature distinguishes two types of $\beta$-convergence: unconditional (or absolute) and conditional.

\section{B.1. Unconditional Convergence}

We say that there is unconditional convergence if small firms tend to grow faster than large ones. We employ the following regression to test for unconditional convergence

$$
i_{i, t+1}=\alpha+\beta k_{i, t}+\varepsilon_{i, t+1} .
$$

When $\beta<0$ we have unconditional convergence. 4 We normalize a firm's capital stock by the average firm's capital stock to ensure stationarity as well as for convenience of interpretation in light of the aggregate investment decomposition in (1) 5

\section{B.2. Conditional Convergence}

The notion of unconditional convergence requires small firms to grow faster than large ones regardless of differences in the determinants of their own optimal investment rate. In fact, unconditional convergence relies on the assumption that the only difference among firms lies in their initial levels of capital. However, firms may differ in their levels of technology, the competitive environment in which they operate, structure of corporate governance, and other factors potentially affecting a firm's optimal investment rate. The

\footnotetext{
${ }^{4}$ Unconditional $\beta$-convergence at the firm level can also be interpreted as a specific violation of Gibrat's Law or Law-of-Proportionate Effects - i.e. independence between a firm's growth and its size.

${ }^{5}$ As shown in Gala and Julio (2010), the main empirical results at the firm level remain unaffected if we use a firm's size.
} 
notion of conditional convergence accounts for differences in the determinants of a firm's optimal investment rate. If all firms share the same optimal investment rate, then the two forms of convergence coincide.

We say that there is conditional convergence if small firms tend to grow faster than large ones holding constant the optimal investment rate of each firm. We test for conditional convergence by augmenting the regression in (2) as follows

$$
i_{i, t+1}=\alpha+\beta k_{i, t}+\theta X_{i, t}+\varepsilon_{i, t+1}
$$

where $X_{i, t}$ includes variables that proxy for a firm's optimal investment rate. If the estimate of $\beta$ is negative once $X_{i, t}$ is held constant, then we say that the data set exhibits conditional convergence.

\section{Aggregate Investment Dynamics}

The firm-level convergence analysis provides useful guidance to identify explanatory variables suitable for explaining the dynamics of aggregate investment. Consider the baseline model of firm-level investments in (3). The aggregation of such a model of conditional convergence leads to the following aggregate investment specification:

$$
i_{t+1} \equiv E^{i}\left[i_{i, t+1} k_{i, t}\right]=\gamma+\theta X_{t}+\beta \operatorname{Var}^{i}\left[k_{i, t}\right]+\varepsilon_{t+1}
$$

where $\gamma \equiv(\alpha+\beta)$ and $X_{t} \equiv E^{i}\left[X_{i, t} k_{i, t}\right]$. The last equality follows from $\operatorname{Var}^{i}\left[k_{i, t}\right]=$ $E^{i}\left[k_{i, t}^{2}\right]-1$. When $X_{i, t}$ represent firm-level characteristics scaled by a firm's capital, $X_{t}$ denote the corresponding aggregate counterparts. The last term in (41) - i.e. the crosssectional variance of firms' sizes - represents a departure from a standard aggregate investment specification in a representative economy. The conditional convergence at the firm-level makes the cross-sectional variance of firms' sizes relevant for aggregate investment dynamics. An increase in the degree of size inequality across firms dampens aggregate investment, ceteris paribus. The stronger the conditional convergence, the stronger the negative impact on economic growth. 


\section{Empirical Analysis}

In this section, after describing the data used in the empirical analysis, we conduct formal tests for firm-level convergence and measure its impact on aggregate investment. We then compare actual aggregate investment data to values of the aggregate investment rate as predicted by the firm-level investment model in (3) and its aggregated counterpart in (44). Finally, we show how the inclusion of distributional considerations improves the performance of standard aggregate linear investment equations.

\section{A. Data}

We construct a sample of firms for the empirical analysis from the combined annual research, full coverage, and industrial COMPUSTAT files for the years 1962 to 2006. We keep all firm-years in our sample that have nonmissing information available to construct the primary variables of interest, namely investment in property, plant and equipment (Compustat data item 128), capital (net property, plant and equipment; item 8), book value of total assets (item 6), market value of assets (book value of assets plus the market value of common stock minus the book value of common stock), earnings before extraordinary items (item 18), depreciation (item 14), stock price at the fiscal year close (item 199), and the number of common shares outstanding (item 25). We deflate capital expenditures and net property, plant and equipment by the deflator for non-residential investment from the NIPA tables. The remaining data items are deflated using the consumer price index. We eliminate any firm-year observation with negative accounting values for total assets, book equity, capital and investment, and in which a firm made a major acquisition. We then trim the variables of interest (investment rates, Q, cash flow rate and capital) at the 1st and 99th percentiles to reduce the impact of extreme values which are common for ratios in firm panels drawn from accounting data. This procedure yields a sample of 140,245 firm-years observations representing 15,342 different firms.

The four main variables used in this study (investment rate, Tobin's Q, cash flow rate, and firm relative size) are calculated as follows. Investment rate $(i)$ is defined as 
capital expenditures in property, plant and equipment scaled by the beginning-of-year capital stock. The capital stock $(K)$ is defined as net property, plant and equipment. Tobin's $\mathrm{Q}(Q)$ is defined as the market value of assets scaled by the book value of assets. Cash flow rate $(C F)$ is calculated as the sum of end-of-year earnings and depreciation scaled by the beginning-of-year capital stock. Finally, firm relative size $(k)$ is the ratio of beginning-of-year firm $i$ 's capital stock to the cross-sectional average of beginningof-year firms' capital stock. Table I summarizes the descriptive statistics for the main variables of interest at both the firm and aggregate level in the full sample.

\section{B. Aggregate Investment Decomposition}

The aggregate investment decomposition (11) emphasizes the importance of the joint distributional dynamics of firm investment rate and relative size in understanding the behavior of aggregate investment rates. The contribution of such distributional dynamics can be conveniently measured by the "distributional wedge". Panel A of Figure I plots the time-series of the aggregate investment rate against the cross-sectional average of firm investment rates. Over the period 1962-2006, the aggregate investment rate averages about $18.5 \%$ and has an annual volatility of about $2.2 \%$. By contrast, the average firm investment rate averages about $28.5 \%$ and has an annual volatility of $3.7 \%$. This last one is always above the aggregate investment rate implying that the distributional wedge is negative over the entire sample period. While the two series tend to comove positively with a correlation coefficient of about 0.38 , the gap between the two series widens substantially after the mid-80s. On average, the cross-sectional average of firm investment rates exceeds the aggregate investment rate by about $10 \%$ with a serial correlation-adjusted t-statistics of about 14. Hence, the distributional wedge is on average negative and strongly statistically significant. This evidence implies a strong economically and statistically significant negative relationship between firm investment rates and relative size. Figure I (Panel B) plots the time-series of the distributional wedge. On average the distributional wedge accounts in absolute value for about $56 \%$ of aggregate investment rate. As expected it is always below zero over the entire sample 
period and it has an annual volatility of $3.5 \%$. In addition, the distributional wedge tends to widen during expansions and to shrink during recessions.

The existence of a negative relationship between firm investment rates and relative size has substantial implications in the aggregate. A "mean-preserving" increase in the cross-sectional dispersion of firm investment rates depresses aggregate investment. Intuitively, a "mean-preserving" increase in the cross-sectional dispersion of firm investment rates shifts the mass towards the tails of its distribution, while keeping the mean constant. The negative relation between investment rate and relative size makes small firms grow faster than big firms. This redistribution of firm investment rates across firms with different relative size depresses aggregate investment because a capital-weighted average of investment rates assigns more weight to firms with larger relative size, which now have even lower investment rates. The stronger the negative relationship between firm investment rate and relative size, the stronger the negative impact of a "meanpreserving" increase in spread.

The empirical evidence suggests that aggregate investment is negatively related the cross-sectional dispersion of firm investment rate and relative size, when controlling for the average investment rate. As shown in Panel $\mathrm{C}$ of Figure I, there is variation over the sample period in the cross-sectional dispersion of firm investment rate, $\sigma^{i}\left(i_{i, t}\right)$, with a standard deviation over time of about 4.4\%. Similarly, as shown in Panel D of Figure I, there is substantial variation over the sample period in the cross-sectional dispersion of firm relative size, $\sigma^{i}\left(k_{i, t}\right)$, with a standard deviation over time of about $24 \%$. Even without controlling for the average investment rate, $\sigma^{i}\left(i_{i, t}\right)$ and $\sigma^{i}\left(k_{i, t}\right)$ tend to comove negatively with aggregate investment rate, with a correlation coefficient of about -0.18 and -0.35 , respectively.

When controlling for the average firm investment rate, a one standard deviation increase in the cross-sectional dispersion of firm investment rates leads to an average decrease of $1.6 \%$ in aggregate investment rates. Similarly, a one standard deviation increase in the cross-sectional dispersion of relative size leads to an average decrease of $0.8 \%$ in aggregate investment rates. 


\section{Firm-Level Convergence}

We report empirical tests of convergence at the firm level in Table II. We begin by testing for unconditional convergence as specified in (2). The first column reports the estimation results without year and firm fixed effects. The results provide strong evidence of unconditional convergence: smaller firms grow faster than large firms. A one standard deviation increase in a firm's relative size reduces on average a firm's investment rate by a statistically significant $3.6 \%$ per annum.

We test for conditional convergence using the investment specification in (3), where we include Tobin's Q and cash flow rate as control variables for heterogeneity in firms' investment opportunities and/or financial status. This choice of controls is motivated by a large literature on firm-level investment. For instance, Eberly, Rebelo and Vincent (2006), among others, argue that investment regressions should include no more than a proxy for Tobin's Q. Cash flow rate has also been shown to be an important determinant of firm-level investment, though the interpretation of its significance has been vigorously debated. The second column in Table II reports the coefficient estimates of a regression of firm investment rates on Tobin's Q, cash flows and relative size. In line with existing empirical evidence, both coefficients on Tobin's Q and cash flows are positive and statistically significant. The coefficient on relative size picks up the convergence effect, conditional on Tobin's Q and cash flows. Its estimate is negative and strongly statistically significant. A one standard deviation increase in a firm's relative size reduces on average a firm's investment rate by about $2.0 \%$ per annum.

The remaining columns in Table II report the results of the same convergence tests with firm and firm-year fixed effects, respectively. Across all specifications, the coefficient on relative size is negative, statistically significant and similar in economic magnitude. The empirical evidence of convergence at the firm level is consistent with the findings in Gala and Julio (2010), who further document its robustness to measurement errors, sample selection, nonlinear specifications of the investment regression, different estimation horizons, different proxies of investment opportunities and financial status, and international samples. 


\section{Aggregate Investment Dynamics}

Estimation of the firm-level investment regression in (3) suggests the existence of economically and statistically significant conditional convergence. We now investigate the economic impact of firm-level convergence on the dynamics of aggregate investment by estimating the aggregated linear investment specification in (44), relating aggregated values of investment to aggregated fundamentals. When the true relationship between investment and fundamentals exhibits conditional convergence, higher moments of the firm relative size distribution should also affect investment.

Panel A of Figure 2 plots the behavior of aggregate investment rate against aggregate Tobin's Q for the period 1964-2006. The series of Tobin's Q while does a good job in tracking the decline in investment rate up to the mid 70's, performs rather poorly afterwards, especially from the early 80's onwards. The correlation coefficient between investment and Tobin's Q over the entire sample period is only about 0.20. For comparison, Panel B plots aggregate investment against aggregate cash flow rate. Similarly, aggregate cash flow tracks the behavior of investment rates reasonably well up to the late 70 's, while performing rather poorly afterwards, especially during the 90's. The correlation coefficient between investment and cash flows over the entire sample is about 0.45. Panel $\mathrm{C}$ and $\mathrm{D}$ plot the first difference of aggregate investment rate against the first difference of Tobin's Q and aggregate cash flow rate, respectively. The corresponding correlation coefficients between the series in first differences are 0.21 and 0.26 , respectively. While the relation between investment and Tobin's $\mathrm{Q}$ is not a tight one at both low and high frequencies, the relation between investment and cash flows appears to be relatively stronger at both high and low frequencies. In order to quantify more accurately the tightness of the relations among these aggregate series we report the results of regressions of aggregate investment on each of these variables in Table III. The dependent variable is the first difference of aggregate investment, $I / K$. The independent variables are first differences of aggregate Tobin's Q, cash flow rate, $C F / K$, and cross-sectional variance of firm relative size, $\operatorname{Var}^{i}\left[k_{i, t}\right]$. The first difference specification reflects a wellknown feature of empirical aggregate investment equations, the presence of a highly serially correlated disturbance term when run in levels. We report the Durbin-Watson 
statistic for the null hypothesis of no serial correlation in the disturbance term. In all specification we cannot reject the null hypothesis at conventional significance levels.

Table III confirms the presence of a weak positive relationship between investment and Tobin's Q, though not statistically significant at conventional levels. This result is consistent with previous findings in Abel and Eberly (2002), and the international evidence in Eberly (1997). The relationship between investment and aggregate cash flow is also positive, though only marginally statistically significant. Tobin's Q and cash flow together can explain only up to $10 \%$ of the variation in aggregate investment. Only cash flow is statistically significant at ten percent level. Adding the cross-sectional variance of firm relative size, $\operatorname{Var}^{i}\left[k_{i, t}\right]$, to the standard investment regression with Tobin's $\mathrm{Q}$ and cash flow substantially improves the explanatory power of aggregate investment dynamics. The adjusted $R^{2}$ increases by 13 percentage points corresponding to a more than threefold increase from the standard investment regression. All the variables together can now explain up to $24 \%$ of the variation in aggregate investment. Figure 3 provides a graphical representation of the goodness of fit across alternative aggregate investment specifications. Accounting for firm-level convergence through the addition of $\operatorname{Var}^{i}\left[k_{i, t}\right]$ in an otherwise standard investment regression not only increases the overall explanatory power of aggregate investment dynamics, but also makes both Tobin's $\mathrm{Q}$ and cash flow strongly statistically significant at one percent level. A one standard deviation increase in aggregate cash flow increases aggregate investment rate by about 1.6 percentage points, which is about 4 times the increase induced by a one standard deviation increase in Tobin's Q. Similarly, the cross-sectional variance of firm relative size is statistically significant at five percent level. A one standard deviation increase in the cross-sectional variance of firm relative size decreases the aggregate investment rate by about 1.4 percentage points. Hence, the economic significance of the impact on aggregate investment of the cross-sectional variance of firm relative size is as large as the impact of aggregate cash flow and four times as large as the impact of aggregate Tobin's Q. 


\section{D.1. Robustness}

The empirical results in Table III provide evidence that accounting for firm-level conditional convergence in aggregate investment regressions through the inclusion of the cross-sectional variance of firm relative size improves substantially the explanatory power of aggregate investment dynamics. Furthermore, the inclusion of the cross-sectional variance of firm relative size in an otherwise standard aggregate investment regression improves substantially the statistical significance of Tobin's Q and cash flow.

We now conduct a large battery of robustness tests to address common problems associated with estimating investment regressions. Table IV reports the estimates from various robustness tests.

The results in Table III might be inadequate if the first difference specification of the aggregate investment regressions does not fully correct for the presence of highly serially correlated disturbance terms when run in levels. In the first column of Table IV, we include one lag of aggregate investment rate to the investment specification in (4). The inclusion of lagged investment rate does affect neither the economic nor the statistical significance of the main results. In addition, the coefficient on lagged investment is not statistically significant at any conventional levels.

The main results might also be affected if there are lags between the time investment opportunities come along and the time actual investment takes place. In the second column of Table IV we include lags of Tobin's Q and cash flow to the standard investment specification. One lag is sufficient to capture dynamics. When both Tobin's Q and cash flow are included in the regression additional lags do not add explanatory power, and even make cash flow statistically insignificant. The third column reports the results of the aggregate investment specification in (4) including one additional lag for each explanatory variable. The inclusion of additional lagged variables does affect neither the economic nor the statistical significance of the main results. The lagged variables are statistically insignificant and do not add explanatory power. The fourth column includes in the previous investment specification also one lag of aggregate investment rate. The results remain economically and statistically unaffected. 
Since we measure Tobin's Q and cash flow at the beginning of the year in which we measure investment, it might be the case that these variables only partially reflect changes in investment profitability over the year. In the fifth column we add current Tobin's Q and cash flow to the standard investment regression in response. There is only a slight increase in the explanatory power. Both beginning-of-year and end-of-year cash flow are statistically significant at conventional levels. Interestingly the coefficients on beginning-of-year and end-of-year Tobin's Q become negative, though statistically insignificant. The negative coefficient is not an uncommon finding in such equations 6 In the sixth column we also include the cross-sectional variance of firm relative size. The main results remain unaffected. Accounting for the firm-level convergence adds explanatory power, with the cross-sectional variance of firm relative size and both beginning-ofyear and end-of-year cash flow being statistically significant at conventional levels.

However, the investment regression so specified is likely to be subject to simultaneity bias. Thus, in the seventh column we use two lagged values of Tobin's Q and cash flow as instruments for their end-of-year counterparts. Our earlier conclusion is slightly affected: only the cross-sectional variance of firm relative size and the beginning-of-year cash flow are statistically significant at conventional levels, thus retaining most of the explanatory power for aggregate investment. The coefficients on beginning-of-year and end-of-year Tobin's Q are negative, though statistically insignificant.

Another potential concern with the interpretation of the tests in Table III is that we are using a noisy proxy for Tobin's Q. If the measurement error in our measure of Tobin's $\mathrm{Q}$ is correlated with the cross-sectional variance of firm relative size, our estimates could be biased. In our first approach to dealing with potential measurement error in our proxy for Tobin's Q, we employ a classical errors-in-variables approach by instrumenting for Tobin's Q. We use two sets of instruments: (i) lagged cash flow; and (ii) lagged cash flow and Tobin's Q. The results of the instrumental variables estimation are reported in the first two columns of Table V. In both cases, the cross-sectional variance of firm relative size shares very similar magnitude and statistical significance with previous results. While cash flow remains strongly statistically and economically significant, Tobin's Q is

\footnotetext{
${ }^{6}$ Although based on different data and time periods, it is also present in Blanchard, Rhee and Summers (1993), and Mork, Shleifer and Vishny (1990).
} 
statistically significant at conventional levels only when instrumented with lagged cash flow.

As a second approach to address the concern of measurement error, we investigate whether the quality of our proxy for Tobin's Q can explain the consistently negative coefficient we obtain on the cross-sectional variance of firm relative size in the investment regressions. To test whether measurement error is driving the sign of this coefficient, we employ the reverse regression bounds methodology of Erickson and Whited (2005). It is well known that if the coefficients from the direct regression have the same sign as those in the reverse regression, then the coefficient in the true regression must also have the same sign (Krasker and Pratt (1986)). The last column of Table V reports the results of the reverse regression methodology. The cross-sectional variance of firm relative size maintains its negative sign in the reverse regression, suggesting that our main results are not due to potential measurement error in our proxy for Tobin's Q.

Recognizing the mild skewness in the distribution of aggregate investment rates, we use the percentage change in investment rates (log differences) as the dependent variable. The first four columns of Table VI report the results for the same investment regression specifications in Table III. Our earlier conclusion is confirmed: the inclusion of the crosssectional variance of firm relative size in an otherwise standard investment specification not only adds explanatory power, but also improves substantially the significance of Tobin's Q and cash flow. Similarly, the remaining four columns in Table VI report the results for the same investment regression specifications where now all variables are in log differences. The empirical results fully support our previous conclusions.

We consider, but do not report for brevity, a number of alternative specifications of our baseline investment regression: (1) we include several lags of Tobin's $Q$ and cash flow as independent variables; (2) to reduce the influence of outliers we (i) deflate investment and cash flow by total assets rather than capital, and (ii) trimmed relevant firm variables at different percentiles of their unconditional distribution. The results are qualitatively and statistically robust to all these alternatives. 


\section{E. Actual versus Predicted Investment Rate}

In this section we assess the importance of firm-level conditional convergence by comparing the aggregate rate of investment observed in the data to that predicted by the firm-level investment model in (3) and its aggregated counterpart in (44). This gauges how well the firm-level estimates fare with the aggregated firm-level estimates in predicting aggregate values. The linear investment specification exhibiting conditional convergence could be better estimated on aggregated values of fundamentals to reduce the impact of firm-specific "noise". However, given the well-known difficulties aggregate specifications of Tobin's Q models have encountered (see for instance Abel and Blanchard (1986)), this comparison is not obvious.

The estimation results of the (first-difference) firm-level investment specification in (3) are first used to obtain predicted values of changes in firm investment rates. The actual values and the estimated values are each aggregated across firms for a given year. This produces an implied time series of changes in aggregate investment rates in the data, as well as estimated by the firm-level investment specification. The $R^{2}$ of a regression of the actual changes in aggregate investment rates on that predicted by the firm-level investment specification in (3) is about $7.8 \%$. The $R^{2}$ associated with the aggregate investment specification in (44) compared to the actual aggregate data is about $23.8 \%$. Figure 4 plots the actual versus the predicted changes in aggregate investment rates according to the investment specification in (3) and (44). The plots along with the associated $R^{2}$ indicate that the aggregate investment specification in (44) does a much better job in predicting aggregate investment rates than the firm-level investment specification in (3). Hence, when accounting for conditional convergence, the firm-level investment specification performs substantially better when based on aggregated firmlevel data as it reduces firm-specific "noise".

However, when ignoring conditional convergence, the standard firm-level investment equation including Tobin's Q and cash flow performs only marginally better in predicting aggregate investment rates when based on aggregated firm-level data. Figure 5 plots the actual versus the predicted changes in aggregate investment rates according to the standard firm-level investment specification including Tobin's Q and cash flow only, and 
its aggregated counterpart. Predicting aggregate investment rates based on the firmlevel estimates leads to an $R^{2}$ of about $9.5 \%$ versus an $R^{2}$ of about $10.0 \%$ when using estimates from aggregated firm-level data.

Overall, accounting for conditional convergence improves substantially the forecasting performance of standard aggregate linear investment equations.

\section{F. Aggregate Investment Dynamics: NIPA Aggregate Series}

The previous section demonstrated that including the cross-sectional variance of firm relative size significantly improves the explanatory power of aggregate investment dynamics. We have focused so far on aggregated firm-level Compustat data as we can only observe the complete size distribution for the firms in the Compustat sample. However, while large and publicly traded, these firms represent only a (significant) subset of the entire population of firms in the US economy. As such, the aggregate series based on aggregated firm-level data may not reflect accurately actual aggregate investment dynamics. To address this concern, we estimate the aggregate investment time-series regression in (44) using the aggregate NIPA series instead of the Compustat aggregated data. Specifically, we use the series on private nonresidential fixed investment and the corresponding current stock of capital from the Bureau of Economic Analysis.

Figure 6 compares the first-differenced NIPA aggregate investment rate with the aggregated Compustat counterpart. The Compustat aggregated investment series is slightly more volatile than its NIPA counterpart through the 1980s and mid 2000s. However, the dynamics of the two series are overall very similar across the entire sample period. This is not surprising as a substantial portion of aggregate data comes from relatively large firms that are likely to be included in the Compustat sample.

Table VIII reports the results of the NIPA aggregate investment regressions. The specification is similar to that reported in Table III, with the exceptions that investment rates, Tobin's Q and cash flow rate are based on NIPA aggregates, while the crosssectional variance of relative firm size is calculated each year from Compustat 7 . The

\footnotetext{
${ }^{7}$ The measure of aggregate Tobin's Q is constructed from the flow of funds as in Hall (2001).
} 
coefficients reported in Table VIII have the same sign and are similar in magnitude to the aggregated regressions reported in Table III. Interestingly, the inclusion of the crosssectional variance of firm size in the traditional augmented Q-type regression makes cash flow no longer significant. Overall, the results in Table VIII confirm that the crosssectional variance of firm size affects significantly the dynamics of aggregate investment.

\section{Concluding Remarks and Discussion}

This paper has examined the impact of the distributional dynamics of firm-level investment on aggregate investment rates. We decompose aggregate investment into two components: the equal-weighted average of firm investment rates plus the crosssectional covariance between firm investment rates and their relative size. This second component, or "distributional wedge", accounts for on average as much as $56 \%$ of the aggregate investment rate, suggesting that the heterogeneity of firm size and investment rates are important determinants of aggregate growth.

Following Gala and Julio (2010), we also establish conditional convergence in firm investment rates. That is, firm-level investment rates are negatively related to firm size, controlling for Tobin's Q and cash flow. We investigate the implications of firmlevel convergence for aggregate investment dynamics. The addition of the cross-sectional variance of firm relative size to the aggregate investment regression significantly increases the explanatory power of the regression. Specifically, we find that the inclusion of the cross-sectional variance term increases the $R^{2}$ of the regression by a factor of three. In addition to an improved statistical fit, the economic significance of the cross-sectional variance of firm relative size is substantial, being as large as the impact of aggregate cash flow and four times as large as that of aggregate Tobin's Q. These findings are robust to a wide variety of robustness tests.

Our findings contribute to the literature on aggregate investment by documenting that the distributional dynamics of firm-level investment significantly improves the explanatory power of standard Tobin's aggregate investment regressions. Furthermore, our findings also contribute to the relatively new literature related to the implications 
of microeconomic investment frictions on aggregates. We contribute to this literature by showing how a firm-level property of investment, namely conditional convergence, affects the dynamics of aggregate investment.

Finally, the finding that the heterogeneity in firm-level investment rates and size are important in explaining aggregate investment dynamics casts some doubt on using representative-economy analysis in studying aggregate investment. That is, models that abstract from firm heterogeneity in size are bound to ignore an important dimension of heterogeneity for understanding aggregate investment dynamics. Thus, in our view, our findings suggest that explaining aggregate investment may require going beyond the standard representative agents' economy. 


\section{References}

[1] Abel, A.B., 1979, Investment and the Value of Capital (Garland, New York).

[2] Andrew B. Abel; Olivier J. Blanchard, 1986, "The Present Value of Profits and Cyclical Movements in Investment", Econornetrica, Vol. 54, No. 2 (Mar., 1986), 249-274.

[3] Abel and Eberly (2002), "Investment and q with Fixed Costs: An Empirical Analysis", Working Paper, University of Pennsylvania.

[4] Abel, Andrew B., and Janice C. Eberly, 1994, A Unified Model of Investment under Uncertainty, American Economic Review 84, 1369-1384.

[5] Barro, Robert J., 1990, The Stock Market and Investment, The Review of Financial Studies, Vol. 3, No. 1, 16-18, 115-131.

[6] Bertola, Guiseppe and Ricardo J. Caballero, "Irreversibility and Aggregate Investment", The Review of Economic Studies, Vol. 61, No. 2 (Apr., 1994), 223-246.

[7] Blanchard, Olivier, Changyong Rhee, Lawrence Summers, 1993, "The Stock Market, Profit, and Investment", The Quarterly Journal of Economics, February 1993.

[8] Caballero, Ricardo J. (2000) "Aggregate Investment: Lessons from the Previous Millenium"

[9] Caballero, Ricardo J. (2007), "Aggregate Investment", Handbook of Macroeconomics,

[10] Caballero, Ricardo J.; Eduardo M. R. A. Engel, "Dynamic (S,s) Economies", Econometrica, Vol. 59, No. 6 (Nov., 1991), 1659-1686.

[11] Caballero, Ricardo J.; Eduardo M. R. A. Engel, "Microeconomic Adjustment Hazards and Aggregate Dynamics", The Quarterly Journal of Economics, May 1993, 433 (2), 359-383.

[12] Caballero, Ricardo J.; Eduardo M. R. A. Engel; John C. Haltiwanger "Plant-Level Adjustment and Aggregate Investment Dynamics", Brookings Papers on Economic Activity, Vol. 1995, No. 2 (1995), 1-54. 
[13] Caballero, Ricardo J.; Eduardo M. R. A. Engel, "Explaining Investment Dynamics in U.S. Manufacturing: A Generalized(S,s) Approach", Econometrica, Vol. 67, No. 4 (Jul., 1999), 783-826.

[14] Cooley, Thomas F. and Vincenzo Quadrini, "Financial Markets and Firm Dynamics"

[15] Doms, M., and T. Dunne (1993), "An investigation into capital and labor adjustment at the plant level", mimeograph (Center for Economic Studies, Census Bureau).

[16] Eberly, Janice, C., 1997, "International evidence on investment and fundamentals", European Economic Review 41 (1997) 1055- 1078.

[17] Eberly, Janice, Sergio Rebelo, and Nicolas Vincent, "Investment and Value: A Neoclassical Benchmark" (2008)

[18] Erickson, T. and Toni Whited, 2000, Measurement Error and the Relationship between Investment and Q, The Journal of Political Economy, 108: 5. 1027-1057.

[19] Erickson, T. and Toni Whited, 2005, Proxy-quality thresholds: Theory and applications, Finance Research Letters, 2, 121-151.

[20] Krasker, W.S., Pratt, J.W., 1986. Bounding the effects of proxy variables on regression coefficients. Econometrica 54, 641-655.

[21] Gabaix, Xavier, 2011. The Granular Origins of Aggregate Fluctuations, Econometrica, 79: 733-772.

[22] Gala, Vito D., 2006, "Investment and Returns", Ph.D. Dissertation, The University of Chicago Booth School of Business.

[23] Gala, Vito D. and Brandon Julio, "Convergence in Corporate Investments", Working Paper, London Business School, 2010.

[24] Gomes, Joao, 2001, Financing Investment, The American Economic Review, 91: 1263-1285.

[25] Gourio, Francois and Anil K Kashyap, "Investment spikes: New facts and a general equilibrium exploration", Journal of Monetary Economics 54 (2007) 1-22 
[26] Hassett, Kevin A. and Glenn Hubbard, "Tax Policy and Investment", in A.J. Auerbach, ed., Fiscal Policy: Lessons from Economic Research, Cambridge: MIT Press, 1997.

[27] Eisner, R. (1978), Factors in Business Investment (National Bureau of Economic Research, Cambridge).

[28] Fazzari, Steven M.; R. Glenn Hubbard; Bruce C. Petersen (1988) "Financing Constraints and Corporate Investment", Brookings Papers on Economic Activity, Vol. 1988, No. 1. (1988), pp. 141-206.

[29] Hayashi, Fumio, Tobin's Marginal q and Average q: A Neoclassical Interpretation, Econornetrica, Vol. 50, No. 1 (Jan., 1982), 213-224.

[30] Hennessy, Christopher, 2004, Tobin's Q, Debt Overhang and Investment, Journal of Finance Vol. 59(4), 1717-1742.

[31] Stein, Jeremy C., "Agency, Information and corporate investment", in Handbook of The Economics of Finance (2003).

[32] Thomas, J.K., 2002. Is lumpy investment relevant for the business cycle. Journal of Political Economy CX, 508-534.

[33] Tobin, J., 1969, A General Equilibrium Approach to Monetary Theory, Journal of Money, Credit and Banking, 1, 1529. 


\section{Table I}

\section{Summary Statistics}

This table reports summary statistics for the primary variables used in this paper. The summary statistics are reported at the firm level (Panel A) and at the aggregate level (Panel B). The data is from the COMPUSTAT database for the years 1962 through 2006. Investment rate $\left(I_{i} / K_{i}\right)$ is defined as capital expenditures in property, plant and equipment scaled by the beginning-of-year capital stock. The capital stock $\left(K_{i}\right)$ is defined as net property, plant and equipment. Tobin's $\mathrm{Q}\left(Q_{i}\right)$ is defined as the market value of assets scaled by the book value of assets. Cash flow rate $\left(C F_{i} / K_{i}\right)$ is calculated as the sum of end-of-year earnings and depreciation scaled by the beginning-of-year capital stock. Firm relative size $\left(k_{i}\right)$ is the ratio of beginning-of-year firm $i$ 's capital stock to the crosssectional average of beginning-of-year firms' capital stock. Aggregate series are obtained by aggregating firm-level data (for example, the aggregate investment rate is the ratio of the sum of firm investments over the sum of firm capital stock). Aggregate capital is the cross-sectional average value of net property, plant and equipment of all firms.

\begin{tabular}{|c|c|c|c|c|c|c|}
\hline & \multicolumn{6}{|c|}{ Panel A: Firm Level } \\
\hline & $\mathrm{N}$ & Mean & St. Dev. & P25 & Median & $\mathrm{P} 75$ \\
\hline$I_{i} / K_{i}$ & 140,245 & 0.29 & 0.29 & 0.11 & 0.20 & 0.36 \\
\hline$C F_{i} / K_{i}$ & 140,245 & 0.64 & 1.04 & 0.14 & 0.38 & 0.80 \\
\hline$Q_{i}$ & 140,245 & 1.56 & 1.05 & 0.94 & 1.20 & 1.75 \\
\hline \multirow[t]{3}{*}{$k_{i}$} & 140,245 & 1.00 & 3.00 & 0.02 & 0.08 & 0.45 \\
\hline & \multicolumn{6}{|c|}{ Panel B: Aggregate Level } \\
\hline & $\mathrm{N}$ & Mean & St. Dev. & $\mathrm{P} 25$ & Median & $\mathrm{P} 75$ \\
\hline$I / K$ & 43 & 0.19 & 0.02 & 0.17 & 0.18 & 0.20 \\
\hline$C F / K$ & 43 & 0.21 & 0.12 & 0.10 & 0.16 & 0.32 \\
\hline$Q$ & 43 & 0.80 & 0.13 & 0.74 & 0.77 & 0.86 \\
\hline $\operatorname{Var}\left(k_{i}\right)$ & 43 & 8.92 & 1.38 & 7.99 & 9.42 & 9.87 \\
\hline
\end{tabular}




\section{Table II}

\section{Investment Regressions: Firm-Level Convergence}

This table reports estimates from regressions of the type:

$$
\frac{I_{i, t+1}}{K_{i, t}}=\alpha+\beta k_{i, t}+\theta X_{i, t}+\varepsilon_{i, t+1}
$$

where the left hand side is firm investment rate. The right hand side variables include firm relative size $k_{i, t}$ and the control variables, $X_{i, t}$, such as Tobin's Q, $Q_{i, t}$ and cash flow rate, $C F_{i, t} / K_{i, t-1}$. Standard errors are clustered by firm and are reported in parentheses. Numbers in bold, underlined and in italics are statistically significant at the $1 \%, 5 \%$ and $10 \%$ level, respectively. The sample period is 1962 to 2006 .

\begin{tabular}{lcccccc}
\hline \hline & $(1)$ & $(2)$ & $(3)$ & $(4)$ & $(5)$ & $(6)$ \\
\hline$k_{i}$ & -0.012 & -0.007 & -0.013 & -0.009 & -0.008 & -0.008 \\
& $(\mathbf{0 . 0 0 1})$ & $(\mathbf{0 . 0 0 0})$ & $(\mathbf{0 . 0 0 1})$ & $(\mathbf{0 . 0 0 1})$ & $(\mathbf{0 . 0 0 1})$ & $(\mathbf{0 . 0 0 1})$ \\
$Q_{i}$ & & 0.067 & & 0.064 & & 0.064 \\
& & $(\mathbf{0 . 0 0 4})$ & & $(\mathbf{0 . 0 0 3})$ & & $(\mathbf{0 . 0 0 3})$ \\
$C F_{i} / K_{i}$ & & 0.087 & & 0.087 & & 0.084 \\
& & $(\mathbf{0 . 0 0 2})$ & & $(\mathbf{0 . 0 0 2})$ & & $(\mathbf{0 . 0 0 2})$ \\
\hline Observations & 140,245 & 140,245 & 140,245 & 140,245 & 140,245 & 140,245 \\
$\bar{R}^{2}$ & 0.02 & 0.20 & 0.02 & 0.20 & 0.01 & 0.20 \\
Firm Effects & No & No & Yes & Yes & Yes & Yes \\
Year Effects & No & No & No & No & Yes & Yes \\
\hline
\end{tabular}


Table III

\section{Aggregate Investment Regressions}

This table reports estimates from regressions of the type:

$$
\Delta\left(\frac{I_{t}}{K_{t-1}}\right)=\gamma+\beta \Delta \operatorname{Var}\left[k_{i t}\right]+\theta \Delta X_{t}+\epsilon_{t},
$$

where the left hand side is aggregate investment rate. The right hand side variables include the cross-sectional variance of firm relative size, $\operatorname{Var}^{i}\left[k_{i, t}\right]$, and the control variables, $X_{t}$, such as Tobin's $\mathrm{Q}, Q_{t}$ and cash flow rate, $C F_{t} / K_{t-1}$. The standard errors reported in parenthesis are corrected for heteroskedasticity and serial correlation using Newey-West methodology with one lag. A constant term is included, but not reported. Coefficient estimates are based on first-differencing of the variables. Newey-West standard errors are reported in parentheses. Numbers in bold, underlined and in italics are statistically significant at the $1 \%, 5 \%$ and $10 \%$ level, respectively. DW is the Durbin-Watson statistic for serially-correlated error terms. The sample period is 1962 to 2006.

\begin{tabular}{lcccc}
\hline \hline & $(1)$ & $(2)$ & $(3)$ & $(4)$ \\
\hline$\Delta Q_{t}$ & 0.019 & & 0.017 & 0.027 \\
& $(0.013)$ & & $(0.011)$ & $(\mathbf{0 . 0 1 0})$ \\
$\Delta C F_{t} / K_{t-1}$ & & 0.082 & 0.075 & 0.127 \\
& & $(0.043)$ & $(0.038)$ & $(\mathbf{0 . 0 3 2})$ \\
$\Delta \operatorname{Var}\left(k_{i, t}\right)$ & & & & -0.010 \\
& & & & $(\underline{0.004})$ \\
\hline DW & $\mathbf{1 . 7 4}$ & $\mathbf{1 . 7 7}$ & $\mathbf{1 . 7 5}$ & $\mathbf{1 . 9 7}$ \\
Observations & 42 & 42 & 42 & 42 \\
Adj. $R^{2}$ & 0.02 & 0.04 & 0.05 & 0.18 \\
$R^{2}$ & 0.04 & 0.07 & 0.10 & 0.24 \\
\hline
\end{tabular}




\section{Table IV}

\section{Aggregate Investment Regressions: Robustness}

This table reports estimates from regressions of the type:

$$
\frac{I_{t+1}}{K_{t}}=\gamma+\beta \operatorname{Var}^{i}\left[k_{i, t}\right]+\theta X_{t}+\varepsilon_{t+1}
$$

where the left hand side is aggregate investment rate. The right hand side variables include the cross-sectional variance of firm relative size, $\operatorname{Var}^{i}\left[k_{i, t}\right]$, and the control variables, $X_{t}$, such as Tobin's $\mathrm{Q}, Q_{t}$ and cash flow rate, $C F_{t} / K_{t-1}$. Coefficient estimates are based on first-differencing of the variables. The standard errors reported in parenthesis are corrected for heteroskedasticity and serial correlation using Newey-West methodology with one lag.

\begin{tabular}{|c|c|c|c|c|c|c|c|}
\hline & (1) & $(2)$ & (3) & (4) & $(5)$ & (6) & (7) \\
\hline$\Delta Q_{t+1}$ & & & & & $\begin{array}{l}-0.015 \\
(0.022)\end{array}$ & $\begin{array}{l}-0.009 \\
(0.018)\end{array}$ & \\
\hline$\Delta C F_{t+1} / K_{t}$ & & & & & $\begin{array}{c}0.092 \\
(\underline{0.040})\end{array}$ & $\begin{array}{c}0.069 \\
(\underline{0.030})\end{array}$ & \\
\hline$I V: \Delta Q_{t+1}$ & & & & & & & $\begin{array}{l}-0.003 \\
(0.030)\end{array}$ \\
\hline$I V: \Delta C F_{t+1} / K_{t}$ & & & & & & & $\begin{array}{l}-0.081 \\
(0.110)\end{array}$ \\
\hline$\Delta Q_{t}$ & $\begin{array}{c}0.025 \\
(\mathbf{0 . 0 0 9})\end{array}$ & $\begin{array}{c}0.026 \\
(0.017)\end{array}$ & $\begin{array}{c}0.030 \\
(0.018)\end{array}$ & $\begin{array}{c}0.030 \\
(0.017)\end{array}$ & $\begin{array}{l}-0.001 \\
(0.022)\end{array}$ & $\begin{array}{c}0.014 \\
(0.019)\end{array}$ & $\begin{array}{l}-0.021 \\
(0.021)\end{array}$ \\
\hline$\Delta C F_{t} / K_{t-1}$ & $\begin{array}{c}0.121 \\
(\mathbf{0 . 0 3 4})\end{array}$ & $\begin{array}{c}0.039 \\
(0.046)\end{array}$ & $\begin{array}{c}0.089 \\
(0.047)\end{array}$ & $\begin{array}{c}0.088 \\
(0.048)\end{array}$ & $\begin{array}{c}0.084 \\
(0.042)\end{array}$ & $\begin{array}{c}0.128 \\
(\mathbf{0 . 0 3 4})\end{array}$ & $\begin{array}{c}0.125 \\
(\underline{0.049})\end{array}$ \\
\hline$\Delta \operatorname{Var}\left(k_{i, t}\right)$ & $\begin{array}{l}-0.010 \\
(\underline{0.004})\end{array}$ & & $\begin{array}{l}-0.009 \\
(\underline{0.003})\end{array}$ & $\begin{array}{l}-0.009 \\
(\underline{0.004})\end{array}$ & & $\begin{array}{l}-0.009 \\
(\underline{0.003})\end{array}$ & $\begin{array}{l}-0.006 \\
(\underline{0.003})\end{array}$ \\
\hline$\Delta Q_{t-1}$ & & $\begin{array}{c}0.020 \\
(0.021)\end{array}$ & $\begin{array}{c}0.015 \\
(0.025)\end{array}$ & $\begin{array}{c}0.014 \\
(0.026)\end{array}$ & & & \\
\hline$\Delta C F_{t-1} / K_{t-2}$ & & $\begin{array}{l}-0.044 \\
(0.050)\end{array}$ & $\begin{array}{l}-0.021 \\
(0.040)\end{array}$ & $\begin{array}{l}-0.022 \\
(0.050)\end{array}$ & & & \\
\hline$\Delta \operatorname{Var}\left(k_{i, t-1}\right)$ & & & $\begin{array}{l}-0.003 \\
(0.004)\end{array}$ & $\begin{array}{l}-0.003 \\
(0.005)\end{array}$ & & & \\
\hline$\Delta I_{t} / K_{t-1}$ & $\begin{array}{c}0.001 \\
(0.135) \\
\end{array}$ & & & $\begin{array}{c}0.010 \\
(0.170) \\
\end{array}$ & & & \\
\hline $\mathrm{DW}$ & 1.99 & 1.66 & 1.84 & 1.86 & 1.76 & 1.95 & 1.85 \\
\hline Observations & 41 & 41 & 41 & 41 & 41 & 41 & 40 \\
\hline $\operatorname{Adj} . R^{2}$ & 0.15 & 0.03 & 0.13 & 0.10 & 0.08 & 0.17 & 0.05 \\
\hline$R^{2}$ & 0.23 & 0.13 & 0.26 & 0.26 & 0.17 & 0.28 & 0.17 \\
\hline
\end{tabular}




\section{Table V \\ Aggregate Investment Regressions: Measurement Error}

This table reports estimates from regressions of the type:

$$
\frac{I_{t+1}}{K_{t}}=\gamma+\beta \operatorname{Var}^{i}\left[k_{i, t}\right]+\theta X_{t}+\varepsilon_{t+1}
$$

where the left hand side is aggregate investment rate. The right hand side variables include the cross-sectional variance of firm relative size, $\operatorname{Var}^{i}\left[k_{i, t}\right]$, and the control variables, $X_{t}$, such as Tobin's $\mathrm{Q}, Q_{t}$ and cash flow rate, $C F_{t} / K_{t-1}$. Specification (1)-(2) report instrumental variables estimation results using lagged cash flow rate, and lagged cash flow rate and lagged Tobin's Q as instruments for Tobin's Q, respectively. Specification (3) reports the reverse regression estimates using the methodology of Erickson-Whited (2005). The reverse regression is a regression of the proxy for Tobin's $\mathrm{Q}$ on investment rate, cash flow rate and cross-sectional variance of firm relative size. The results from the reverse regressions are re-arranged to put investment on the left-hand side. The standard errors reported in parenthesis are corrected for heteroskedasticity and serial correlation using Newey-West methodology with one lag. A constant term is included, but not reported. Coefficient estimates are based on first-differencing of the variables. Newey-West standard errors are reported in parentheses. Numbers in bold, underlined and in italics are statistically significant at the $1 \%, 5 \%$ and $10 \%$ level, respectively. DW is the Durbin-Watson statistic for serially-correlated error terms. The sample period is 1962 to 2006.

\begin{tabular}{lccc}
\hline \hline & $(1)$ & $(2)$ & $(3)$ \\
\hline$\Delta \operatorname{Var}\left(k_{i, t}\right)$ & -0.008 & -0.010 & -0.030 \\
& $(\mathbf{0 . 0 0 3})$ & $(\underline{0.004})$ & $(0.058)$ \\
$\Delta Q_{t}$ & & & 0.287 \\
& & & $(0.159)$ \\
$\Delta C F_{t} / K_{t-1}$ & 0.107 & 0.139 & 0.140 \\
& $(\mathbf{0 . 0 3 4})$ & $(\mathbf{0 . 0 2 7})$ & $(0.247)$ \\
$\Delta Q_{t}\left(I V: \Delta C F_{t-1} / K_{t-2}\right)$ & 0.055 & & \\
& $(\underline{0.026})$ & & \\
$\Delta Q_{t}\left(I V:\left[\Delta C F_{t-1} / K_{t-2}, \Delta Q_{t-1}\right]\right)$ & & 0.025 & \\
& & $(0.020)$ & \\
\hline DW & $\mathbf{2 . 0 0}$ & $\mathbf{2 . 0 5}$ & \\
Observations & 41 & 41 & 42 \\
$R^{2}$ & 0.20 & 0.20 & 0.18 \\
\hline
\end{tabular}


Table VI

\section{Aggregate Investment Regressions: Robustness}

This table reports estimates from regressions of the type:

$$
\frac{I_{t+1}}{K_{t}}=\gamma+\beta \operatorname{Var}^{i}\left[k_{i, t}\right]+\theta X_{t}+\varepsilon_{t+1}
$$

where the left hand side is the log of aggregate investment rate. The right hand side variables include the cross-sectional variance of firm relative size, $\operatorname{Var}^{i}\left[k_{i, t}\right]$, and the control variables, $X_{t}$, such as Tobin's $\mathrm{Q}, Q_{t}$ and cash flow rate, $C F_{t} / K_{t-1}$, as well as their log values. The standard errors reported in parenthesis are corrected for heteroskedasticity and serial correlation using Newey-West methodology with one lag. A constant term is included, but not reported. Coefficient estimates are based on firstdifferencing of the variables. Newey-West standard errors are reported in parentheses. Numbers in bold, underlined and in italics are statistically significant at the $1 \%, 5 \%$ and $10 \%$ level, respectively. DW is the Durbin-Watson statistic for serially-correlated error terms. The sample period is 1962 to 2006.

\begin{tabular}{|c|c|c|c|c|c|c|c|c|}
\hline & $(1)$ & $(2)$ & (3) & (4) & (5) & (6) & (7) & (8) \\
\hline$\Delta Q_{t}$ & $\begin{array}{c}0.094 \\
(0.068)\end{array}$ & & $\begin{array}{c}0.081 \\
(0.062)\end{array}$ & $\begin{array}{c}0.134 \\
(\underline{0.050})\end{array}$ & & & & \\
\hline$\Delta C F_{t} / K_{t-1}$ & & $\begin{array}{c}0.453 \\
(0.229)\end{array}$ & $\begin{array}{c}0.421 \\
(0.213)\end{array}$ & $\begin{array}{c}0.695 \\
(\mathbf{0 . 1 7 2})\end{array}$ & & & & \\
\hline$\Delta \operatorname{Var}\left(k_{i, t}\right)$ & & & & $\begin{array}{l}-0.053 \\
(\underline{0.021})\end{array}$ & & & & \\
\hline$\Delta \log \left(Q_{t}\right)$ & & & & & $\begin{array}{c}0.070 \\
(0.055)\end{array}$ & & $\begin{array}{c}0.061 \\
(0.052)\end{array}$ & $\begin{array}{c}0.112 \\
(\underline{0.043})\end{array}$ \\
\hline$\Delta \log \left(C F_{t} / K_{t-1}\right)$ & & & & & & $\begin{array}{c}0.190 \\
(\mathbf{0 . 0 6 6})\end{array}$ & $\begin{array}{c}0.186 \\
(\mathbf{0 . 0 6 4})\end{array}$ & $\begin{array}{c}0.253 \\
(\mathbf{0 . 0 5 2})\end{array}$ \\
\hline$\Delta \log \left(\operatorname{Var}\left(k_{i, t}\right)\right)$ & & & & & & & & $\begin{array}{r}-0.474 \\
(\mathbf{0 . 1 5 9}) \\
\end{array}$ \\
\hline$\overline{\mathrm{DW}}$ & 1.74 & 1.76 & 1.74 & 1.95 & 1.73 & 1.87 & 1.84 & 2.10 \\
\hline Observations & 42 & 42 & 42 & 42 & 42 & 42 & 42 & 42 \\
\hline $\operatorname{Adj} . R^{2}$ & 0.01 & 0.05 & 0.05 & 0.17 & 0.01 & 0.15 & 0.15 & 0.27 \\
\hline$R^{2}$ & 0.04 & 0.07 & 0.10 & 0.23 & 0.03 & 0.17 & 0.19 & 0.33 \\
\hline
\end{tabular}


Table VII

\section{Aggregate Investment Regressions: NIPA Data}

This table reports estimates from regressions of the type:

$$
\Delta\left(\frac{I_{t}}{K_{t-1}}\right)=\gamma+\beta \Delta \operatorname{Var}\left[k_{i t}\right]+\theta \Delta X_{t}+\epsilon_{t}
$$

where the left hand side is aggregate investment rate. The right hand side variables include the cross-sectional variance of firm relative size, $\operatorname{Var}^{i}\left[k_{i, t}\right]$, and the control variables, $X_{t}$, such as Tobin's $\mathrm{Q}, Q_{t}$ and cash flow rate, $C F_{t} / K_{t-1}$. The standard errors reported in parenthesis are corrected for heteroskedasticity and serial correlation using Newey-West methodology with one lag. A constant term is included, but not reported. Numbers in bold, underlined and in italics are statistically significant at the 1\%,5\% and $10 \%$ level, respectively. The sample period is 1963 to 2010.

\begin{tabular}{lcccc}
\hline \hline$\Delta Q_{t}$ & 0.0172 & & 0.0157 & 0.0167 \\
& $(\mathbf{0 . 0 0 4})$ & & $(\mathbf{0 . 0 0 4})$ & $(\mathbf{0 . 0 0 5})$ \\
$\Delta C F_{t}$ & & 0.4797 & 0.3109 & 0.2152 \\
& & $(\mathbf{0 . 1 7 4})$ & $(0.192)$ & $(0.198)$ \\
$\Delta \operatorname{Var}\left(k_{i t}\right)$ & & & & -0.0008 \\
& & & & $(\mathbf{0 . 0 0 0})$ \\
\hline Observations & 46 & 46 & 46 & 46 \\
$R^{2}$ & 0.04 & 0.08 & 0.10 & 0.13 \\
\hline
\end{tabular}


Figure 1. Time Series of Investment Rates and Dispersion Measures

This figure plots the time-series of variables of interest over the period 1962-2006. Panel A: aggregate investment rate $(I / K)$ and average investment rate $E_{i}\left(I_{i} / K_{i}\right)$; Panel B: Distributional Wedge, that is $\operatorname{cov}_{i}\left(I_{i} / K_{i}, K_{i} / K\right)$; Panel C: cross-sectional standard deviation of investment rates, $\sigma_{i}\left(I_{i} / K_{i}\right)$; Panel D: cross-sectional standard deviation of firm relative size, $\sigma_{i}\left(K_{i} / K\right)$.
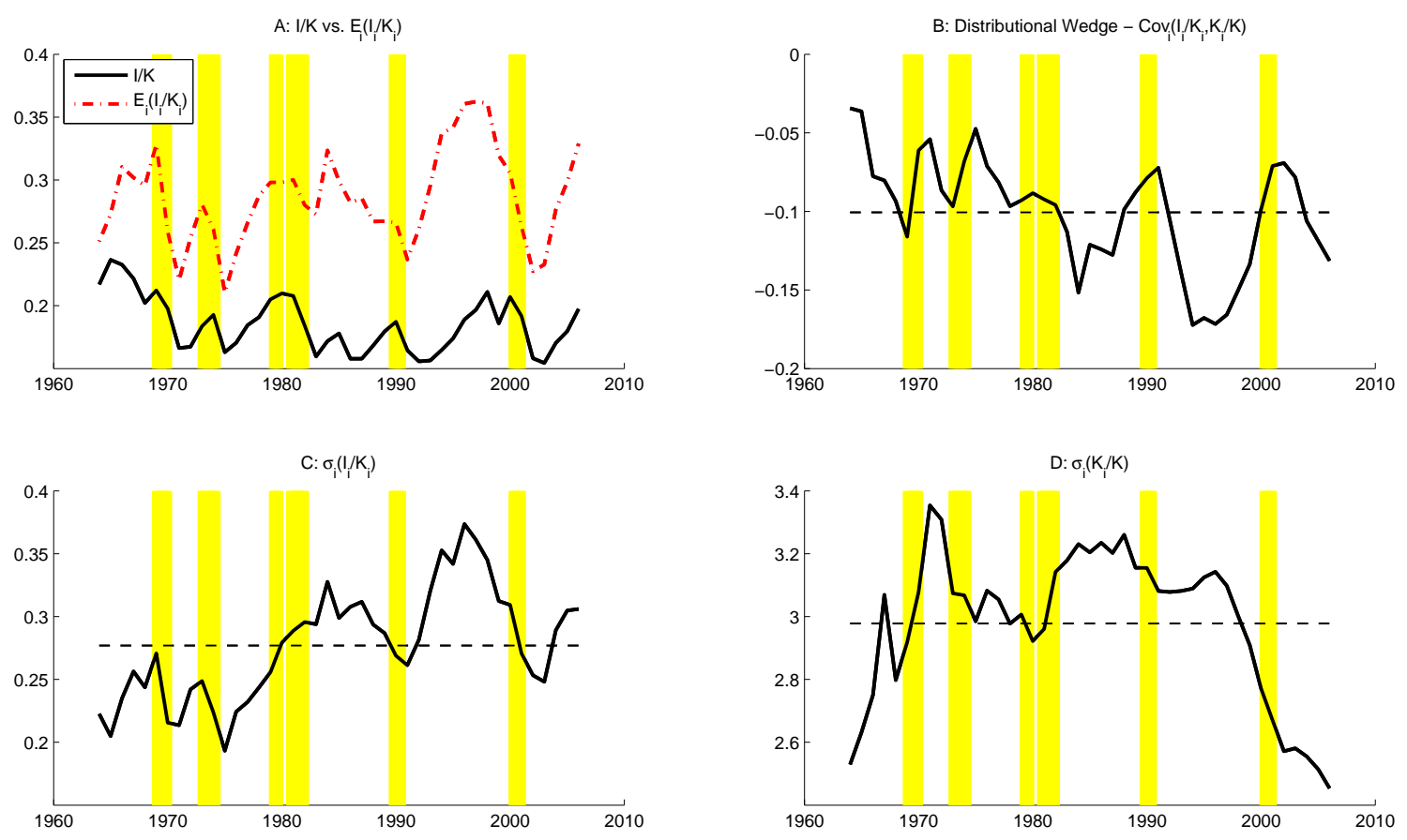
Figure 2. Time Series of Aggregate Variables

This figure plots the time-series of aggregate variables of interest over the period 19622006. Panel A: investment rate $(I / K)$ and Tobin's Q, $Q$; Panel B: investment rate $(I / K)$ and cash flow $(C F / K)$; Panel C: change in investment rate $(I / K)$ and Tobin's $\mathrm{Q}, Q$; Panel D: change in investment rate $(I / K)$ and cash flow $(C F / K)$.
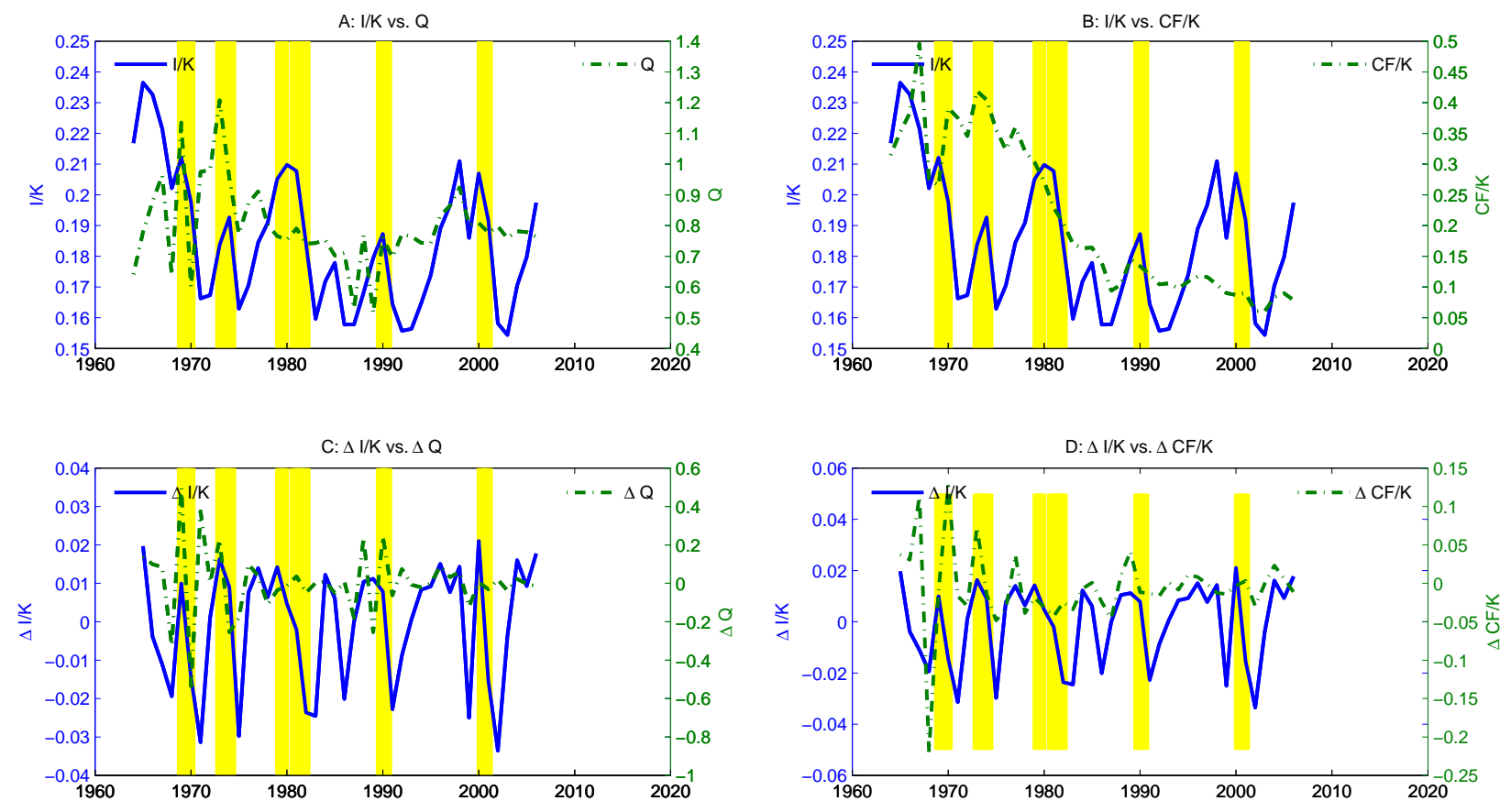
Figure 3. Predicted Vs. Actual Investment Rates

This figure plots the time-series of aggregate variables of interest over the period 1962-2006. Namely, the changes in actual aggregate investment rate $(\Delta I / K)$; changes in aggregate investment rate predicted by the standard investment specification including Tobin's Q and cash flow rate only; and changes in aggregate investment rate predicted by the aggregate investment specification including Tobin's Q, cash flow rate and the cross-sectional variance of firm relative size.

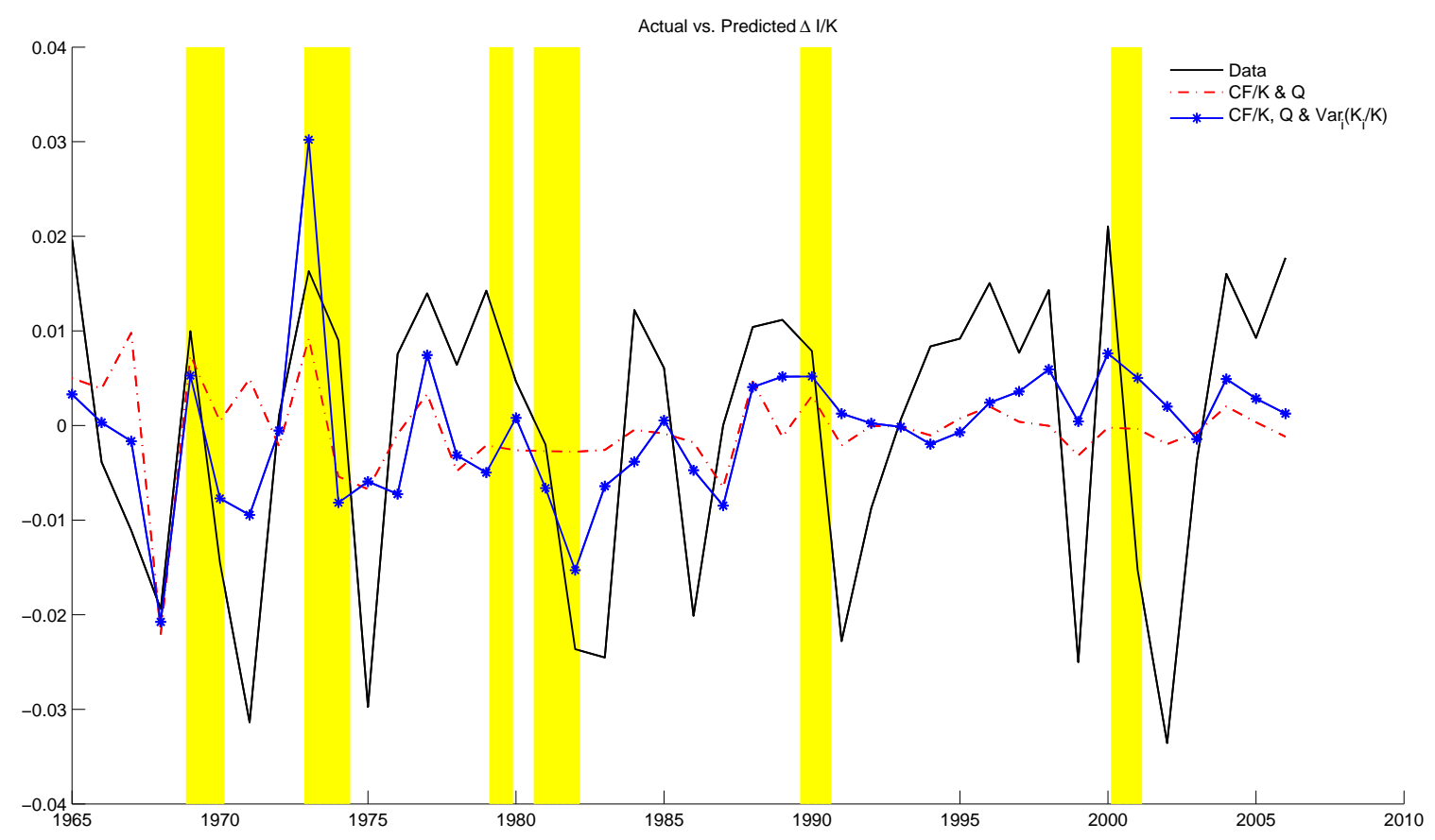


Figure 4. Predicted vs. Actual Investment Rates: Levels

This figure plots the time-series of aggregate variables of interest over the period 19622006. Namely, the changes in actual aggregate investment rate $(\Delta I / K)$; changes in aggregate investment rate predicted by the firm-level investment specification in (3); and changes in aggregate investment rate predicted by the aggregate investment specification in (4).

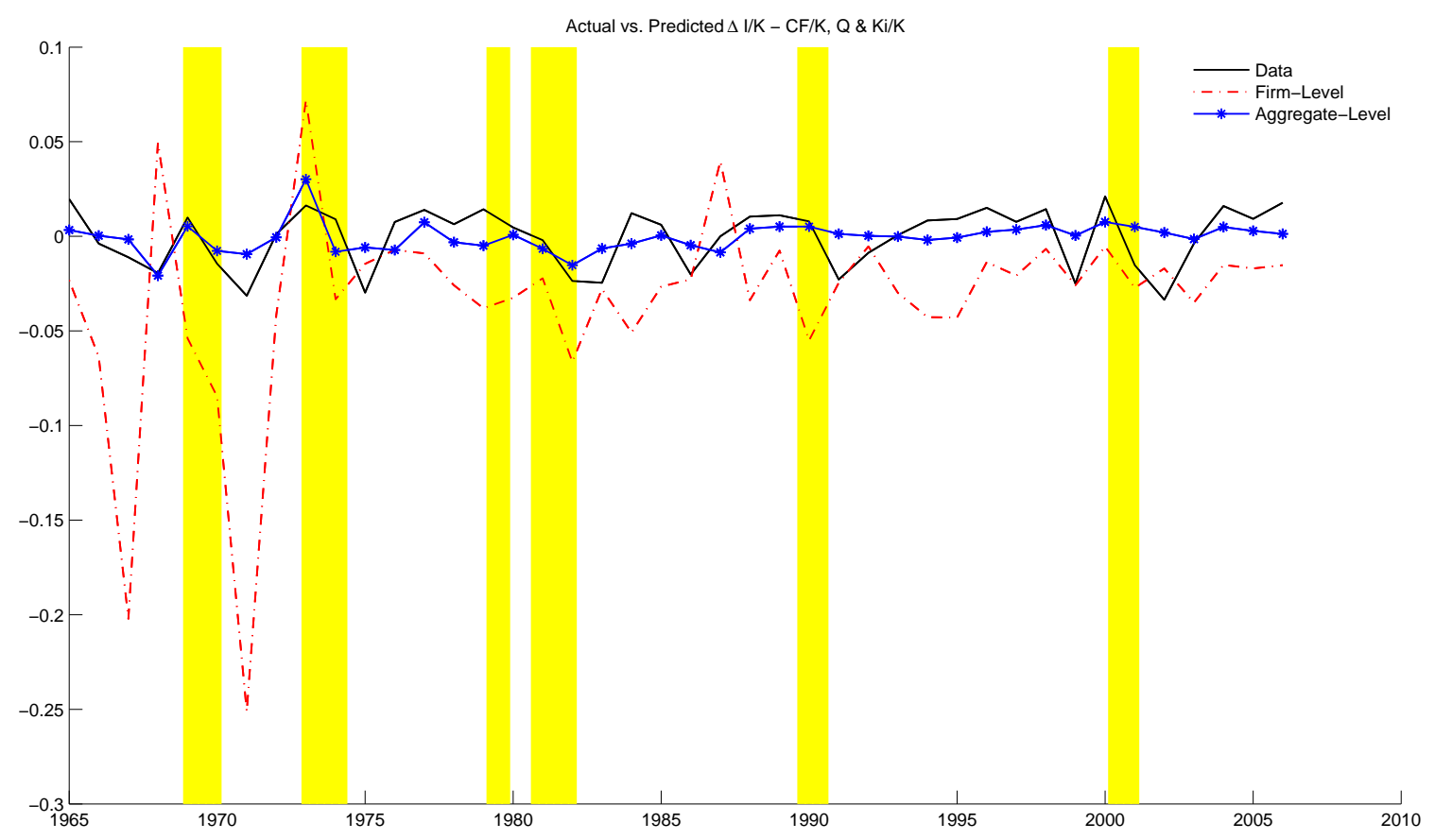


Figure 5. Predicted vs. Actual Investment Rates: Changes

This figure plots the time-series of aggregate variables of interest over the period 1962-2006. Namely, the changes in actual aggregate investment rate $(\Delta I / K)$; changes in aggregate investment rate predicted by the standard firm-level investment specification including Tobin's Q and cash flow rate only; and changes in aggregate investment rate predicted by the standard aggregate investment specification including Tobin's Q and cash flow rate only.

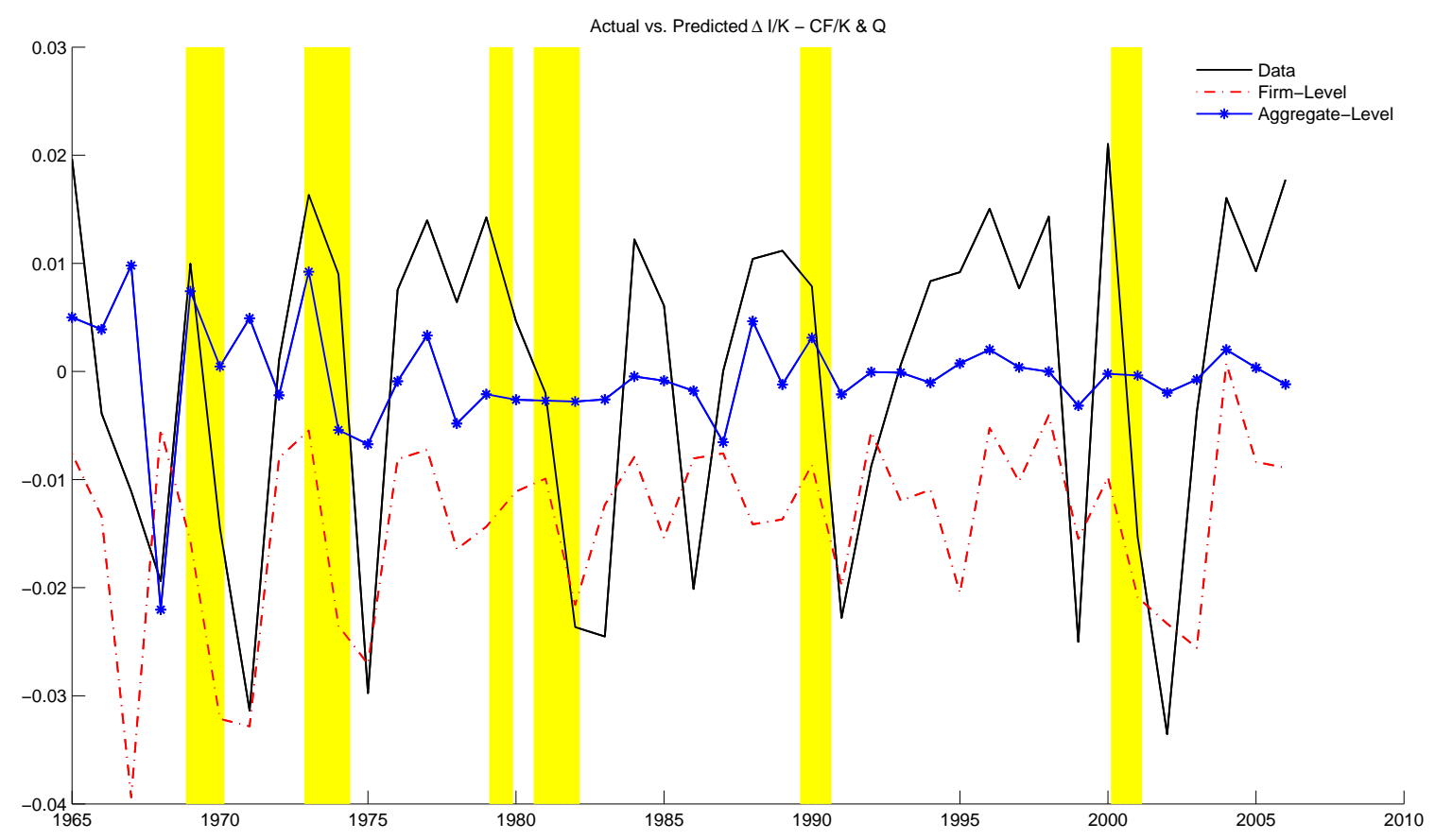


Figure 6. NIPA Aggregate vs. Compustat Aggregated Data

This figure plots the time-series of the changes in actual aggregate investment rate $(\Delta I / K)$ for both the NIPA aggregate data and the aggregated Compustat data. The sample period is 1963 to 2010 .

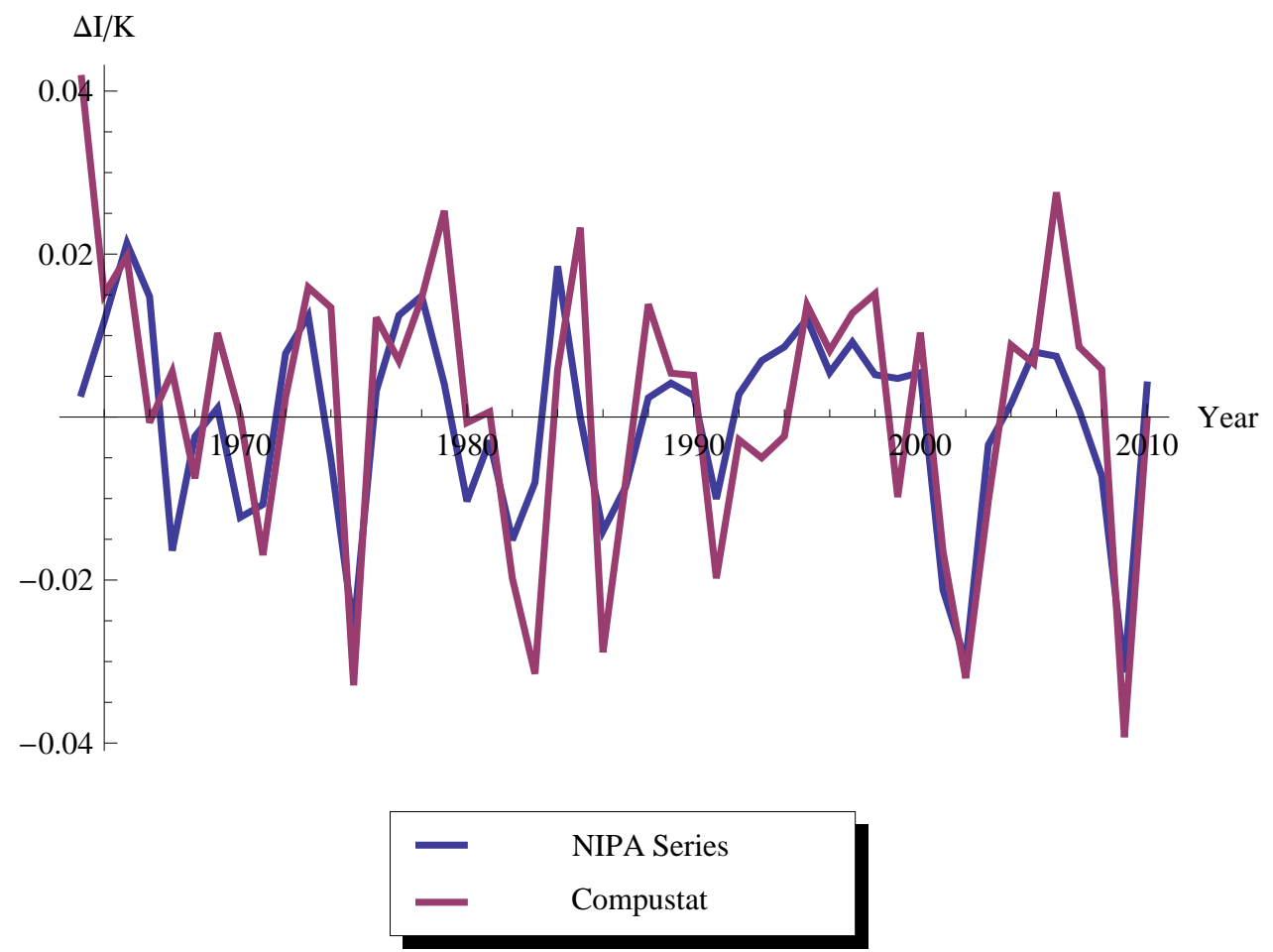

